\title{
Factors of Recurrence After Complete Response in Children with Neuroblastoma: A 16-Year Retrospective Study of 179 Cases
}

\author{
Fan $\mathrm{Li}$ \\ Weiling Zhang \\ Huimin $\mathrm{Hu}$ \\ Yi Zhang \\ Jing Li \\ Dongsheng Huang
}

Department of Pediatrics, Beijing Tongren Hospital, Capital Medical University, Beijing, 100730, People's Republic of China

Correspondence: Dongsheng Huang Department of Pediatrics, Beijing Tongren Hospital, Capital Medical University, Beijing, 100730, People's Republic of China

Tel +86 10-58266032

Email hdsmed@I26.com
Background: It is not clear which known adverse prognostic factors of neuroblastoma are closely associated with tumor recurrence after complete response. We analyzed the factors for post-remission recurrence in children with neuroblastoma through a retrospective study. Methods: A total of 179 children with neuroblastoma who achieved initial complete response were included in this study. Kaplan-Meier method and multivariate Cox regression model were used to assess the factors that may have impact on tumor recurrence after complete response.

Results: The 5-year overall survival rates of the entire cohort $(\mathrm{n}=179)$, recurrence group ( $\mathrm{n}$ $=86)$ and non-recurrence group $(\mathrm{n}=93)$ were $81.9 \%, 66.2 \%$, and $98.7 \%$, respectively. The 5 -year recurrence-free survival (RFS) rates of the entire cohort and the high-risk cohort were $47.3 \%$ and $31.2 \%$, respectively. RFSs were significantly reduced in children with age $\geq 18$ months, INSS stage 4, unfavorable histology, bone marrow metastasis, osseous metastasis, serum NSE level $\geq 100 \mathrm{ng} / \mathrm{mL}$, and serum LDH level $\geq 1400 \mathrm{U} / \mathrm{L}(P<0.05)$. The independent risk factors for post-remission recurrence in the entire cohort were age $\geq 18$ months, unfavorable histology, and serum LDH level $\geq 1400 \mathrm{U} / \mathrm{L}(P<0.05)$. In the high-risk cohort, the independent risk factor for recurrence was serum $\mathrm{LDH} \geq 1400 \mathrm{U} / \mathrm{L}(P<0.05)$. Based on a new recurrence risk stratification, the 5-year RFSs of the children were $93.5 \%, 66.4 \%$, and $22.5 \%$ in the low-risk, intermediate-risk, and high-risk groups, respectively. The area under the ROC curve of the new stratification was 0.773 (95\% CI: 0.704-0.842).

Conclusion: Age $\geq 18$ months, unfavorable histology, and serum LDH level $\geq 1400 \mathrm{U} / \mathrm{L}$ are independent risk factors for post-remission recurrence in children with neuroblastoma. A newly established recurrence risk stratification has diagnostic advantages in predicting risk of recurrence, which is especially suitable for low- and middle-income countries or regions.

Keywords: age, $M Y C N$ amplification, histology, recurrence-free survival, serum lactate dehydrogenase, serum neuron-specific enolase

\section{Introduction}

Neuroblastoma is one of the most common primary malignant tumors in children, accounting for $8 \%$ to $10 \%$ of all childhood cancers and for approximately $15 \%$ of cancer deaths in children. ${ }^{1}$ A previous study reported that the disease-specific survival at $1,2,5$, and 20 years for the entire cohort was $81 \%, 70 \%, 61 \%$, and $59 \%$, respectively. ${ }^{2}$ Despite the fact that the cure rate of neuroblastoma has significantly increased with the combination of surgery, chemoradiotherapy and stem cell transplantation, $50 \%$ to $60 \%$ of patients with high-risk neuroblastoma have 
recurrence, and no curative salvage treatment regimens exist. $^{3}$ Numerous studies have shown that children with recurrent neuroblastoma have a poor prognosis. ${ }^{4-7}$ Tumor recurrence is often accompanied by distant metastasis or the development of new lesions such as central nervous system, ${ }^{8}$ resulting in increased mortality. The mechanism of recurrence after complete response in patients with neuroblastoma remains unclear, and further research on the evidence of factors affecting recurrence has become a prerequisite for preventing post-remission relapse in patients with neuroblastoma.

Although event-free survival (EFS) has been recognized as a very important prognostic indicator for evaluating tumor outcomes, it still has some limitations. The concept of a clinical event is relatively vague, which includes not only the recurrence and progression of a disease but also death from the disease, toxicity, and accidents. In addition, the mechanisms that lead to tumor progression, recurrence, and death may be different, some known prognostic factors including age, INSS stage, metastasis, MYCN status, histological grading, and serum lactate dehydrogenase ( $\mathrm{LDH}$ ) level may not be used to accurately predict post-remission recurrence in patients with neuroblastoma.

In contrast to traditional studies on prognostic factors for childhood neuroblastoma, we independently analyzed the prognostic factors based on recurrence-free survival (RFS) through a retrospective study. The in-depth understanding of the factors of recurrence in this setting may promote the prevention of tumor recurrence as a new therapeutic approach. Moreover, with adjustments to the initial treatment for patients at high risk of recurrence, the rate of post-remission recurrence may significantly reduce, which provide a new approach to improve the long-term outcomes for children with neuroblastoma.

\section{Materials and Methods}

\section{Clinical Materials}

This study was carried out in accordance with the Declaration of Helsinki, and was approved by the Ethics Committee of the Beijing Tongren Hospital, Capital Medical University, Beijing, China (No. 2020-08-SFZXHDS). Written informed consent to participate in the study was obtained from all children's guardians. A retrospective analysis was performed on 376 children with neuroblastoma who were admitted to the Pediatrics Department of the Beijing Tongren Hospital from 2005 to 2020 and who had postoperative pathological confirmation of the diagnosis. From this cohort, 179 children who achieved initial complete response after comprehensive treatment were included in this study. All pathological types were confirmed by initial surgical excision of the primary lesion.

Data for all variables were obtained from electronic medical records. The variables included in the study consisted of demographic variables (age and gender), clinical variables [International Neuroblastoma Staging System (INSS) ${ }^{9}$ stage, International Neuroblastoma Pathology Classification (INPC) ${ }^{10}$ pathological type, primary site, and metastatic sites], and laboratory variables [serum neuronspecific enolase (NSE) and LDH level assessed before initial treatment]. Due to the fact that DNA ploidy, 11q aberration, vanillylmandelic acid (VMA), and homovanillic acid (HVA) information were not available in most cases, these indicators were not included in the statistical analyses.

According to the risk of poor prognosis, the age group was divided into groups under the age of 18 months and at or over the age of 18 months. ${ }^{11,12}$ The amplification status of $M Y C N$ oncogene in tumor tissues was detected by fluorescence in situ hybridization, and amplification was defined when the copy number $>10$. In terms of the serum NSE, the cohort was divided into groups with a level $\geq 100$ $\mathrm{ng} / \mathrm{mL}$ and $<100 \mathrm{ng} / \mathrm{mL}^{13-15}$ Serum LDH level was dichotomized by $1400 \mathrm{U} / \mathrm{L}$ with reference to a recent prognosis study by the International Neuroblastoma Risk Group (INRG). ${ }^{16}$ In some cases, because of the inability to accurately distinguish between retroperitoneal and adrenal space occupation by abdominal ultrasound or CT, they were combined into one category in primary sites. Because there were few cases in INSS stages 2 and $4 \mathrm{~S}$, stages 2, 3, and $4 \mathrm{~S}$ were combined according to the prognosis, ${ }^{17}$ to enable comparison with stage 4 .

In accordance with the International Neuroblastoma Response Classification and previous evaluation criteria, ${ }^{9,18}$ complete response was defined as the complete disappearance of all primary and metastatic diseases for at least 4 weeks with a normal serum NSE and LDH level, and recurrence was defined as a new site of disease following an initial complete response. RFS was calculated from the time of initial treatment to the date of recurrence or last contact. ${ }^{18}$

\section{Treatment Strategy}

With reference to the principles of the Children's Oncology Group (COG), we formulated the treatment plan for neuroblastoma. 
For the low- and intermediate-risk patients, surgical resection combined with chemotherapy was the main treatment. One-stage complete resection was performed for single localized tumor. For patients unable to undergo upfront surgical resection, preoperative chemotherapy of 2-4 cycles were used to reduce volume before surgical resection. Postoperative chemotherapy lasted 2-4 cycles in the low-risk group and 4-6 cycles in the intermediate-risk group. Chemotherapy regimens for the low- and intermediate-risk patients included CBP+VP16 (carboplatin: $560 \mathrm{mg} / \mathrm{m}^{2}$ on day 1 ; etoposide: $120 \mathrm{mg} / \mathrm{m}^{2}$ on day 1 to day 3) and CTX+DOX+VCR (cyclophosphamide: $1.5 \mathrm{~g} / \mathrm{m}^{2}$ on day 1 ; doxorubicin: $25 \mathrm{mg} / \mathrm{m}^{2}$ on day 1 to day 2; vincristine: $1.5 \mathrm{mg} / \mathrm{m}^{2}$ on day 1 ), which were carried out alternately.

For patients in the high-risk group, the treatment was surgery combined with chemotherapy, and myeloablative chemotherapy with autologous peripheral blood stem cell transplantation (APBSCT) was performed for the eligible patients. Preoperative chemotherapy was delivered 3-4 cycles, and postoperative chemotherapy was delivered 4 6 cycles. Chemotherapy regimens for the high-risk patients included TC (topotecan: $1.2 \mathrm{mg} / \mathrm{m}^{2}$ on day 1 to day 5 ; cyclophosphamide: $250 \mathrm{mg} / \mathrm{m}^{2}$ on day 1 to day 5), CDV (cyclophosphamide: $2.1 \mathrm{~g} / \mathrm{m}^{2}$ on day 1 to day 2 , intravenous infusion for 48 hours; doxorubicin: $25 \mathrm{mg} / \mathrm{m}^{2}$ on day 1 to day 3, intravenous infusion for 72 hours; vincristine: $0.67 \mathrm{mg} / \mathrm{m}^{2}$ on day 1 to day 3 , intravenous infusion for 72 hours), and $\mathrm{CiE}$ (cisplatin: $50 \mathrm{mg} / \mathrm{m}^{2}$ on day 1 to day 4; etoposide: $200 \mathrm{mg} / \mathrm{m}^{2}$ on day 1 to day 3 ). Chemotherapy started with 2 cycles of TC regimen, followed by alternating CDV and CiE. For children under one year of age in the high-risk group, PECA regimen (cisplatin: $90 \mathrm{mg} / \mathrm{m}^{2}$ on day 1; etoposide: $100 \mathrm{mg} / \mathrm{m}^{2}$ on day 3 ; doxorubicin: $30 \mathrm{mg} / \mathrm{m}^{2}$ on day 14 ; cyclophosphamide: $150 \mathrm{mg} / \mathrm{m}^{2}$ on day 7 to day 13) was used. Radical or partial resection was performed if the tumor was considered resectable after preoperative chemotherapy. Patients older than 2 years were considered to receive radiotherapy at the site of the primary lesion and metastatic diseases after intensive postoperative chemotherapy. If the tumor did not achieve complete response after postoperative treatment, a continued chemotherapy of 4-6 cycles or a second surgical resection was performed. Four cycles of consolidation chemotherapy or APBSCT was performed once a patient achieved initial complete response. Melphalan, carboplatin, and etoposide were used for pre-treatment of APBSCT (melphalan: $70 \mathrm{mg} / \mathrm{m}^{2}$ on day 1 to day 3; carboplatin: $425 \mathrm{mg} / \mathrm{m}^{2}$ on day 1 to day 4; etoposide: $338 \mathrm{mg} / \mathrm{m}^{2}$ on day 1 to day 4 ). Stem cells were mobilized using recombinant human granulocyte colony-stimulating factor $(5-10 \mu \mathrm{g} / \mathrm{kg}$ until the neutrophil value was greater than $1.5 \times 10^{9} / \mathrm{L}$ ).

In patients with intermediate- and high-risk neuroblastoma, oral 13-cis-retinoic acid consolidation treatment began 60 days after postoperative chemotherapy or APBSCT $\left(160 \mathrm{mg} / \mathrm{m}^{2}\right.$, once every 2 days, 14 days a course of treatment, 6 continuous courses). The treatment protocol is shown in Figure 1.

\section{Evaluation of Treatment Response and Tumor Monitoring After Complete Response}

Serum NSE and LDH were reviewed in each chemotherapy cycle. Imaging examinations at the site of tumor invasion, including MRI, CT, and ultrasound, were reviewed every two chemotherapy cycles. Bone marrow examination and minimal residual disease (MRD) were reviewed every two chemotherapy cycles in patients with bone marrow involvement. In patients with bone metastases, whole-body bone scans were reviewed every 4 chemotherapy cycles. All children underwent ${ }^{123}$ I-MIBG scan or PET/CT before stopping chemotherapy.

After achievement of initial complete response, the serum NSE and LDH were reviewed monthly in the first year, every 2 months in the 2nd to 3rd years, and every 3 months after the 3 rd year. Imaging examinations of primary tumor and metastatic diseases were reviewed every 3 months in the first year, every 4 months in the 2nd to 3rd years, and every 6 months after the 3rd year. In patients with bone marrow metastases, bone marrow examination and MRD were reviewed every 3 months for the first three years, and every 4-6 months after the 3rd year. Once the patient has bone pain, headache or tumor compression symptoms, the serum NSE, serum LDH, imaging examination, and bone marrow examination should be reviewed immediately to determine whether the tumor had recurred.

\section{Statistical Analysis}

The data were analyzed statistically using the SPSS 22.0 software. Continuous variables are described by mean or median, and categorical variables are expressed by frequency and percentage. The Kaplan-Meier method was used for univariate analysis, and the Log rank test was 


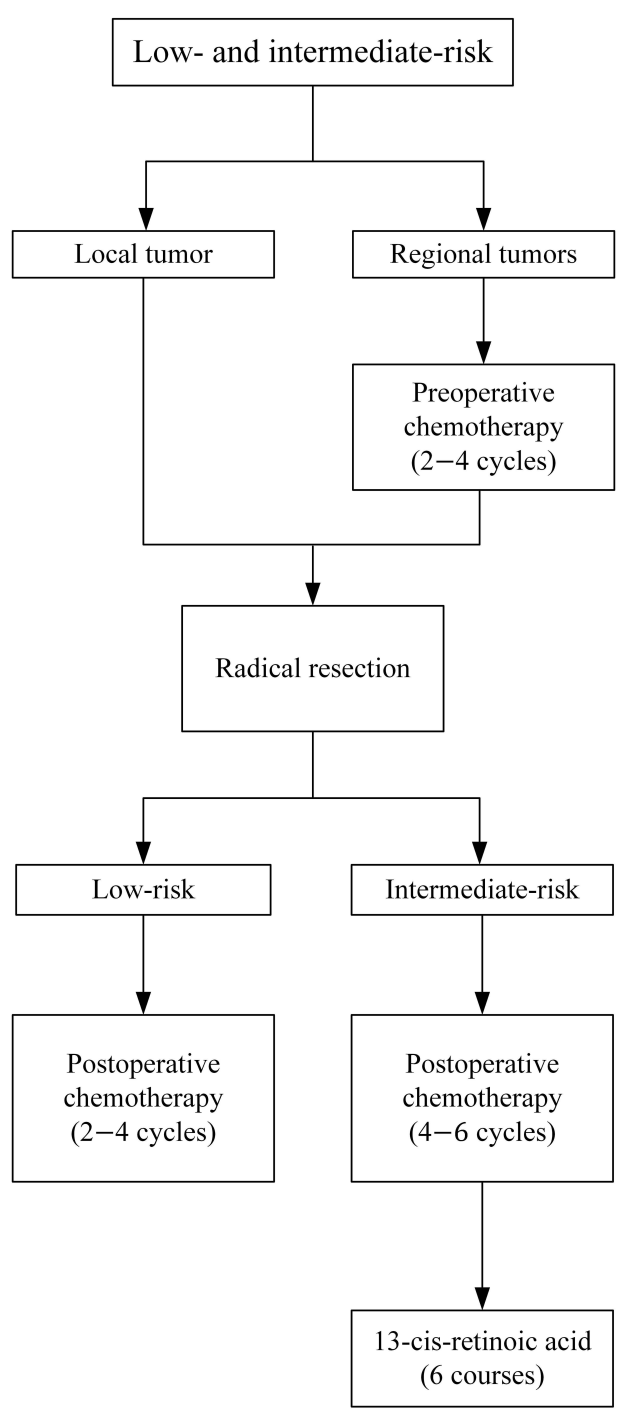

Figure I Treatment protocol.

used to evaluate the difference among univariate factors. A multivariate Cox regression model was used to assess the relationship between risk factors and tumor recurrence. $P<0.05$ indicated that the difference was statistically significant.

\section{Results}

\section{General Data}

Of the 179 children with neuroblastoma in initial complete response, 94 were males and 85 were females. The mean age was $3.47 \pm 2.66$ years, with the minimum and maximum ages being 0 and 14.25 years, respectively. The mean duration of the follow-up was $59.45 \pm 2.08$ months, with a median follow-up of $55.00 \pm 2.49$ months. The demographic and clinical features, including age, gender,
INSS stage, pathological type, primary site, distant metastasis site, MYCN status, serum NSE level, and serum LDH level, of the entire cohort are summarized in Table 1.

Of the 179 children with initial complete response, 86 (48.0\%) relapsed during follow-up period. Among them, single focal in situ recurrence was detected in 8/86 (9.3\%) cases, single focal distant recurrence was detected in 14/86 (16.3\%) cases, and multifocal recurrence was detected in 64/86 (74.4\%) cases. 31/86 (36.0\%) cases had adrenal gland recurrence, 19/86 (22.1\%) cases had mediastinum recurrence, 47/86 (54.7\%) cases had bone marrow recurrence, 45/86 (52.3\%) cases had bone recurrence, 13/86 $(15.1 \%)$ cases had intracranial or meningeal recurrence, $5 / 86(5.8 \%)$ cases had lung or pleural recurrence, $6 / 86$ (7.0\%) cases had liver recurrence, and 16/86 (18.6\%) cases had distant lymph node recurrence. The mean time 
Table I Clinical Features of the Entire Cohort

\begin{tabular}{|c|c|}
\hline & Total $(n=179)$ \\
\hline \multicolumn{2}{|l|}{ Age (months) [n (\%)] } \\
\hline$\geq 18$ & I35 (75.4) \\
\hline$<18$ & $44(24.6)$ \\
\hline \multicolumn{2}{|l|}{ Gender $[\mathrm{n}(\%)]$} \\
\hline Male & $94(52.5)$ \\
\hline Female & $85(47.5)$ \\
\hline \multicolumn{2}{|l|}{ INSS stage [n (\%)] } \\
\hline 2 & $10(5.6)$ \\
\hline 3 & $65(36.3)$ \\
\hline 4 & $98(54.7)$ \\
\hline $4 S$ & $6(3.4)$ \\
\hline \multicolumn{2}{|l|}{ Pathological type [n (\%)] } \\
\hline Neuroblastoma & $104(58.1)$ \\
\hline Ganglioneuroblastoma (nodular) & $47(26.3)$ \\
\hline Ganglioneuroblastoma (intermixed) & $26(14.5)$ \\
\hline Ganglioneuroma & $2(1.1)$ \\
\hline \multicolumn{2}{|l|}{ Primary site [n (\%)] } \\
\hline Adrenal glands/Retroperitoneum & I39 (77.7) \\
\hline Mediastinum & $34(19.0)$ \\
\hline Pelvis & $4(2.2)$ \\
\hline Cervical soft tissue & $\mathrm{I}(0.6)$ \\
\hline Spinal canal & $\mathrm{I}(0.6)$ \\
\hline \multicolumn{2}{|l|}{ Distant metastasis site [n (\%)] } \\
\hline Bone marrow & $70(39.1)$ \\
\hline Bone & $69(38.5)$ \\
\hline Distant lymph node & $39(21.8)$ \\
\hline Liver & $14(7.8)$ \\
\hline Lung & $4(2.2)$ \\
\hline Central nervous system & $3(1.7)$ \\
\hline Other sites (skin, scrotum and ascites) & $3(1.7)$ \\
\hline \multicolumn{2}{|l|}{ MYCN status $[\mathrm{n}(\%)]$} \\
\hline Amplified & $33(18.4)$ \\
\hline Not amplified & $58(32.4)$ \\
\hline Unknown & $88(49.2)$ \\
\hline \multicolumn{2}{|l|}{ Serum NSE level (ng/mL) [n (\%)] } \\
\hline$\geq 100$ & $89(49.7)$ \\
\hline$<100$ & $90(50.3)$ \\
\hline \multicolumn{2}{|l|}{ Serum LDH level (U/L) [n (\%)] } \\
\hline$\geq 1400$ & II (6.I) \\
\hline$<1400$ & $168(93.9)$ \\
\hline
\end{tabular}

Abbreviations: INSS, International Neuroblastoma Staging System; NSE, serum neuron-specific enolase; LDH, serum lactate dehydrogenase.

to recurrence was $26.02 \pm 1.79$ months, with a median time to recurrence of 22.00 months.

\section{Overall Survival of Each Group}

The 5-year overall survival (OS) rate of 179 children with initial complete response was $81.9 \%$. The OS rates of recurrent and non-recurrent children were $66.2 \%$ and
$98.7 \%$, respectively. The 5 -year OS rates of the COG high-, intermediate- and low-risk groups were $75.7 \%$, $95.9 \%$, and $100.0 \%$, respectively. The OS rates in the nonrecurrence group and the intermediate-/low-risk group were significantly higher than those in the recurrence group and the high-risk group, respectively. $(P<0.05)$ (Table 2 and Figure 2).

\section{Analysis of Recurrence Factors in 179 Children with Post-Remission Neuroblastoma Comparison of RFSs in Each Group and Univariate Analysis of the Risk Factors for Post-Remission Recurrence}

The 5-year recurrence-free survival (RFS) rates of the entire cohort, high-risk group, intermediate-risk group, and lowrisk group were $47.3 \%, 31.2 \%, 85.1 \%$, and $88.9 \%$, respectively. The age, gender, INSS stage, histological type, primary site, bone marrow metastasis, osseous metastasis, hepatic metastasis, distant lymph node metastasis, MYCN status, serum NSE level, and serum LDH level of all patients were statistically analyzed. The 1-year, 3-year, and 5-year RFSs of each group were listed (Table 3) and RFS curves were drawn (Figures 3-Figure 5). The results showed that the RFSs of the group with age $\geq 18$ months, INSS stage 4 , unfavorable histology, bone marrow metastasis, osseous metastasis, serum NSE level $\geq 100 \mathrm{ng} / \mathrm{mL}$, and serum LDH level $\geq 1400 \mathrm{U} / \mathrm{L}$ were significantly lower than those of the group with age $<18$ months, INSS stages $2 / 3 / 4 \mathrm{~S}$, favorable histology, non-bone marrow metastasis, non-osseous metastasis, serum NSE level $<100 \mathrm{ng} / \mathrm{mL}$, and serum $\mathrm{LDH}$ level $<1400 \mathrm{U} / \mathrm{L}$, respectively $(P<0.05)$. There were no statistical differences in RFSs among gender, primary site, hepatic metastasis, and distant lymph node metastasis $(P>0.1)$. $M Y C N$ amplification may be associated with reduced RFSs $(0.05<P<0.1)$.

\section{Multivariate Analysis of Risk Factors for Post-Remission Recurrence}

Factors with $P<0.1$ in univariate analysis, including age, INSS stage, histological type, bone marrow metastasis, osseous metastasis, MYCN status, serum NSE level, and serum LDH level were assessed using a multivariate Cox regression model. After variable adjustment, the independent risk factors for post-remission recurrence in patients with neuroblastoma were age $\geq 18$ months, unfavorable histology, and serum LDH level $\geq 1400 \mathrm{U} / \mathrm{L}(P<0.05)$. The hazard ratios of age $\geq 18$ months, unfavorable 
Table 2 Overall Survival of Each Group in Children with Neuroblastoma After Initial Complete Response

\begin{tabular}{|l|c|c|c|c|c|}
\hline & $\mathbf{n}(\%)$ & I-Year OS (\%) & 3-Year OS (\%) & 5-Year OS (\%) & P value \\
\hline Total & $179(100.0)$ & 98.9 & 88.9 & 81.9 & 66.2 \\
Recurrence group & $86(48.0)$ & 97.7 & 86.0 & 98.7 & $<0.001$ \\
Non-recurrence group & $93(52.0)$ & 100.0 & 98.7 & 75.7 & 0.01 \\
High-risk group & $120(67.0)$ & 99.2 & 85.3 & 95.9 & 100.0 \\
Intermediate-risk group & $49(27.4)$ & 98.0 & 95.9 & 100.0 & \\
Low-risk group & $10(5.6)$ & 100.0 & & & \\
\hline
\end{tabular}

Abbreviation: OS, overall survival.

histology, and serum LDH level $\geq 1400 \mathrm{U} / \mathrm{L}$ were 3.017 , 2.813 and 3.644, respectively. INSS stage, bone marrow metastasis, osseous metastasis, MYCN status, and serum NSE level had no significant effect on post-remission recurrence in patients with neuroblastoma $(P>0.05)$ (Table 4).

\section{Analysis of Post-Remission Recurrence Factors in 120 Children with High-Risk Neuroblastoma Comparison of RFSs in Each Group and Univariate Analysis of the Risk Factors for Post-Remission Recurrence}

As shown in Table 3, the recurrence rate of the highrisk group was much higher than that of the low- and intermediate-risk group; in addition, the treatment regimen for high-risk children is different from that for intermediate- and low-risk children, so children in high-risk group were analyzed separately. The 1-year, 3-year, and 5-year RFSs in each group of high-risk children were shown in Table 5 and Figure 6. The results showed that the RFSs of the group with unfavorable histology and serum LDH level $\geq 1400 \mathrm{U} / \mathrm{L}$ were significantly lower than those of the group with favorable histology and serum LDH level $<1400 \mathrm{U} / \mathrm{L}$, respectively $(P<0.05)$. There were no statistical differences in RFSs among gender, INSS stage, primary site, bone marrow metastasis, osseous metastasis, distant lymph node metastasis, $M Y C N$ status, serum NSE level, radiotherapy, and APBSCT $(P>0.1)$. Children older than 18 months or without hepatic metastasis may result in reduced RFSs $(0.05<P<0.1)$.

\section{Multivariate Analysis of Risk Factors for Post-Remission Recurrence}

Factors with $P<0.1$ in univariate analysis, including age, histological type, hepatic metastasis, and serum LDH level were assessed using the multivariate Cox regression model. After variable adjustment, the independent risk factors for post-remission recurrence in high-risk children with neuroblastoma were serum LDH level $\geq 1400 \mathrm{U} / \mathrm{L}(P<0.05)$, with a hazard ratio of 2.803. Age, histological type, and hepatic metastasis had no significant effect on post-remission recurrence in high-risk children with neuroblastoma $(P>0.05)$ (Table 6).
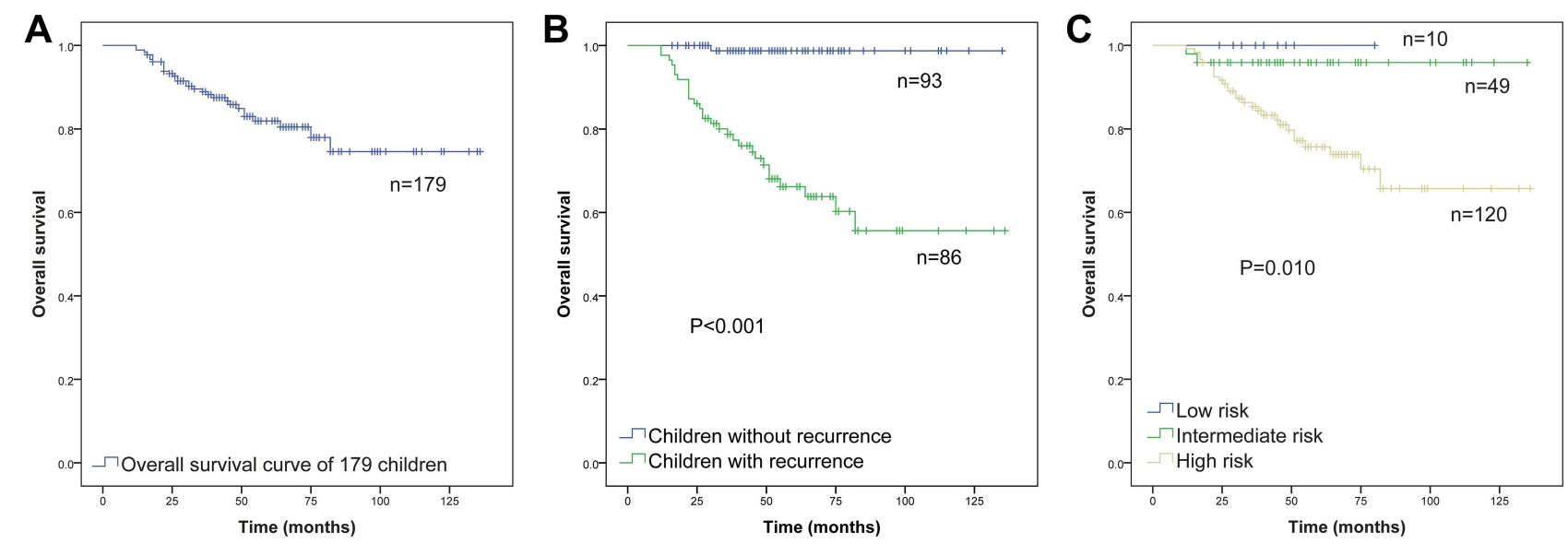

Figure 2 (A) Overall survival (OS) of 179 children with complete response; (B) Comparison of OS between recurrence group and non-recurrence group; (C) Comparison of OS in different COG risk groups. (Kaplan-Meier method, $P$ value shown for Log rank test among variables). 
Table 3 Comparison of RFSs in 179 Children with Neuroblastoma After Initial Complete Response

\begin{tabular}{|c|c|c|c|c|c|}
\hline & n (\%) & I-Year RFS (\%) & 3-Year RFS (\%) & 5-Year RFS (\%) & $P$ value \\
\hline Total & $179(100.0)$ & 94.4 & 60.1 & 47.3 & \\
\hline \multicolumn{6}{|l|}{ COG risk group } \\
\hline High risk & $120(67.0)$ & 90.8 & 47.9 & 31.2 & $<0.001$ \\
\hline Intermediate risk & $49(27.4)$ & 93.9 & 85.1 & 85.1 & \\
\hline Low risk & $10(5.6)$ & 100.0 & 88.9 & 88.9 & \\
\hline \multicolumn{6}{|l|}{ Age (months) } \\
\hline$\geq 18$ & $135(75.4)$ & 91.9 & 53.4 & 36.4 & $<0.001$ \\
\hline$<18$ & $44(24.6)$ & 93.2 & 81.4 & 81.4 & \\
\hline \multicolumn{6}{|l|}{ Gender } \\
\hline Male & $94(52.5)$ & 88.3 & 59.3 & 43.7 & 0.380 \\
\hline Female & $85(47.5)$ & 96.5 & 61.2 & 52.7 & \\
\hline \multicolumn{6}{|l|}{ INSS stage } \\
\hline $2,3,4 \mathrm{~S}$ & $81(45.3)$ & 87.7 & 70.7 & 60.3 & 0.005 \\
\hline 4 & $98(54.7)$ & 95.9 & 51.6 & 37.0 & \\
\hline \multicolumn{6}{|l|}{ Histological type } \\
\hline Unfavorable histology & $100(55.9)$ & 90.0 & 46.8 & 27.0 & $<0.001$ \\
\hline Favorable histology & $79(44.1)$ & 94.9 & 77.4 & 77.4 & \\
\hline \multicolumn{6}{|l|}{ Primary site } \\
\hline Adrenal glands/Retroperitoneum & $139(77.7)$ & 91.4 & 58.3 & 45.7 & 0.467 \\
\hline Others & $40(22.3)$ & 95.0 & 66.7 & 53.2 & \\
\hline \multicolumn{6}{|l|}{ Bone marrow metastasis } \\
\hline Yes & $70(39.1)$ & 95.7 & 50.4 & 36.1 & 0.009 \\
\hline No & $109(60.9)$ & 89.9 & 66.7 & 54.6 & \\
\hline \multicolumn{6}{|l|}{ Osseous metastasis } \\
\hline Yes & $69(38.5)$ & 97.1 & 49.3 & 33.9 & 0.009 \\
\hline No & $110(61.5)$ & 89.1 & 67.3 & 56.3 & \\
\hline \multicolumn{6}{|l|}{ Hepatic metastasis } \\
\hline Yes & $14(7.8)$ & 92.9 & 77.9 & 64.9 & 0.129 \\
\hline No & $165(92.2)$ & 92.1 & 58.6 & 45.7 & \\
\hline \multicolumn{6}{|l|}{ Distant lymph node metastasis } \\
\hline Yes & $39(21.8)$ & 94.9 & 53.6 & 40.8 & 0.254 \\
\hline No & $140(78.2)$ & 91.4 & 62.0 & 49.1 & \\
\hline \multicolumn{6}{|l|}{ MYCN status } \\
\hline Amplified & $33(36.3)$ & 90.9 & 60.6 & 49.9 & 0.090 \\
\hline Not amplified & $58(63.7)$ & 98.3 & 75.5 & 66.9 & \\
\hline \multicolumn{6}{|l|}{ Serum NSE level (ng/mL) } \\
\hline$\geq 100$ & $89(49.7)$ & 91.0 & 45.8 & 32.3 & $<0.001$ \\
\hline$<100$ & $90(50.3)$ & 93.3 & 74.8 & 64.4 & \\
\hline \multicolumn{6}{|l|}{ Serum LDH level (U/L) } \\
\hline$\geq 1400$ & II (6.I) & 72.7 & 9.1 & 9.1 & $<0.001$ \\
\hline$<1400$ & $168(93.9)$ & 93.5 & 63.6 & 49.8 & \\
\hline
\end{tabular}

Abbreviations: RFS, recurrence-free survival; INSS, International Neuroblastoma Staging System; NSE, serum neuron-specific enolase; LDH, serum lactate dehydrogenase.

\section{Establishment of a New Recurrence Risk} Stratification and Comparison with Previous Stratification Systems

Based on the independent recurrence risk factors of age $\geq 18$ months, favorable histology, and serum LDH level $\geq 1400 \mathrm{U} /$ L, a new recurrence risk stratification system was established, which divided the children into three categories: low, intermediate, and high risk. Low risk was defined as the absence of all three risk factors, intermediate risk was defined as the presence of any one of the three risk factors, and high risk was defined as the presence of two or more risk factors. Under this stratification, there were 32/179 (17.9\%) in low-risk group, 55/179 (30.7\%) in intermediate-risk group, and 92/179 (51.4\%) in high-risk group, respectively. 

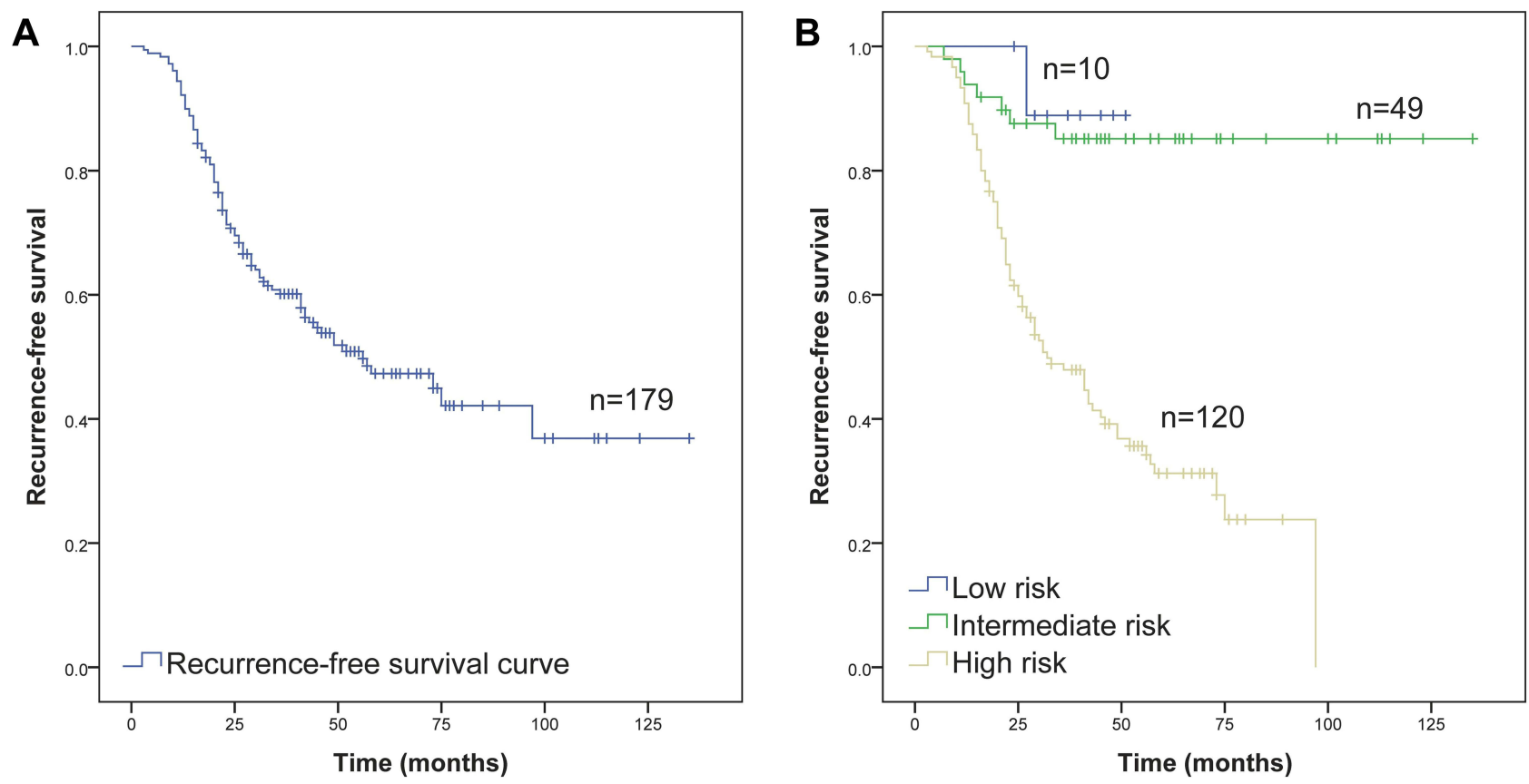

Figure 3 (A) Recurrence-free survival (RFS) of 179 children with complete response; (B) Comparison of RFS in different COG risk groups. (Kaplan-Meier method, P value shown for Log rank test among variables).
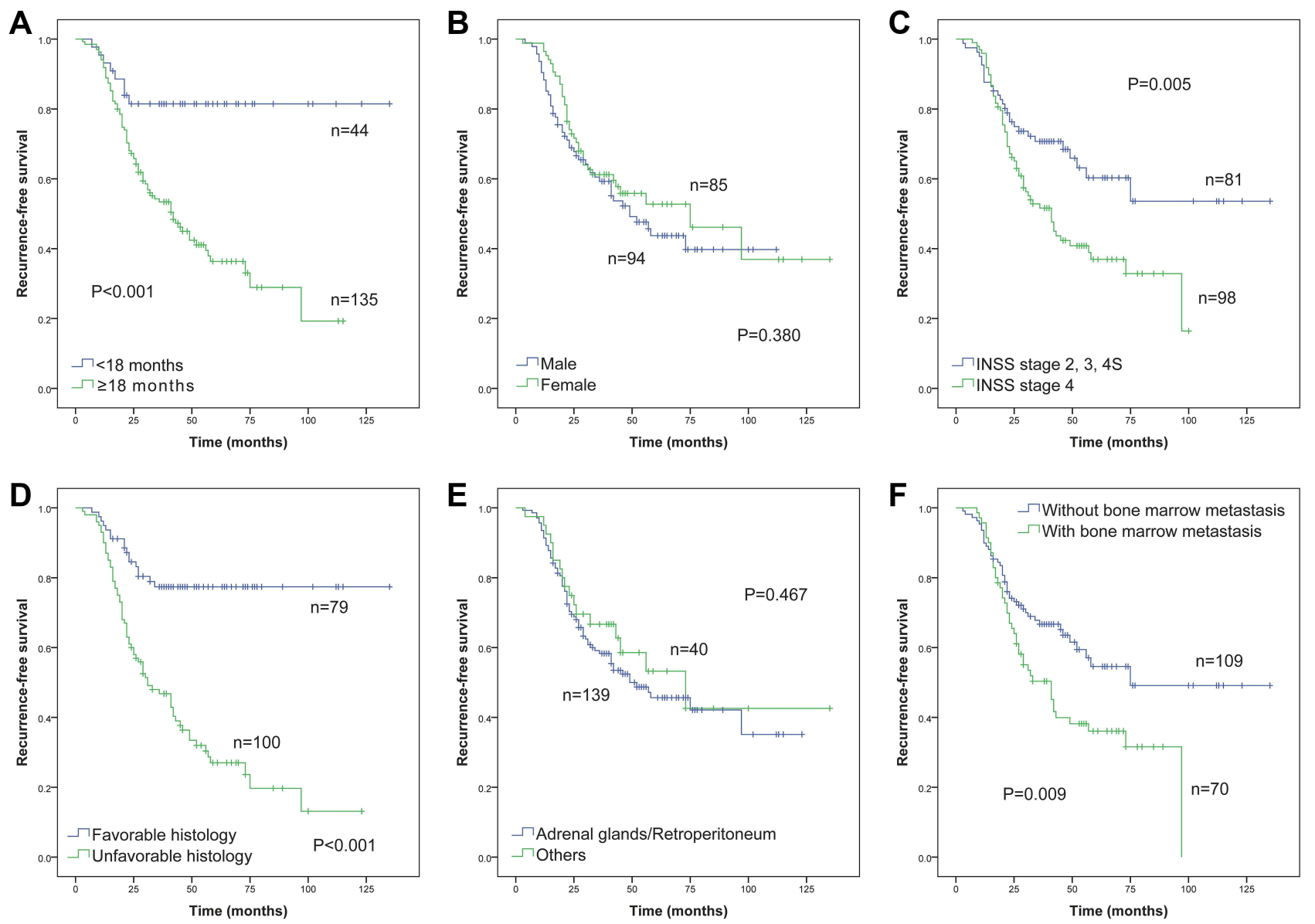

Figure 4 Comparisons of recurrence-free survival by (A) age, (B) gender, (C) INSS stage, (D) histological type, (E) primary site, and (F) bone marrow metastasis in I79 children with neuroblastoma. (Kaplan-Meier method, $P$ value shown for Log rank test among variables). 

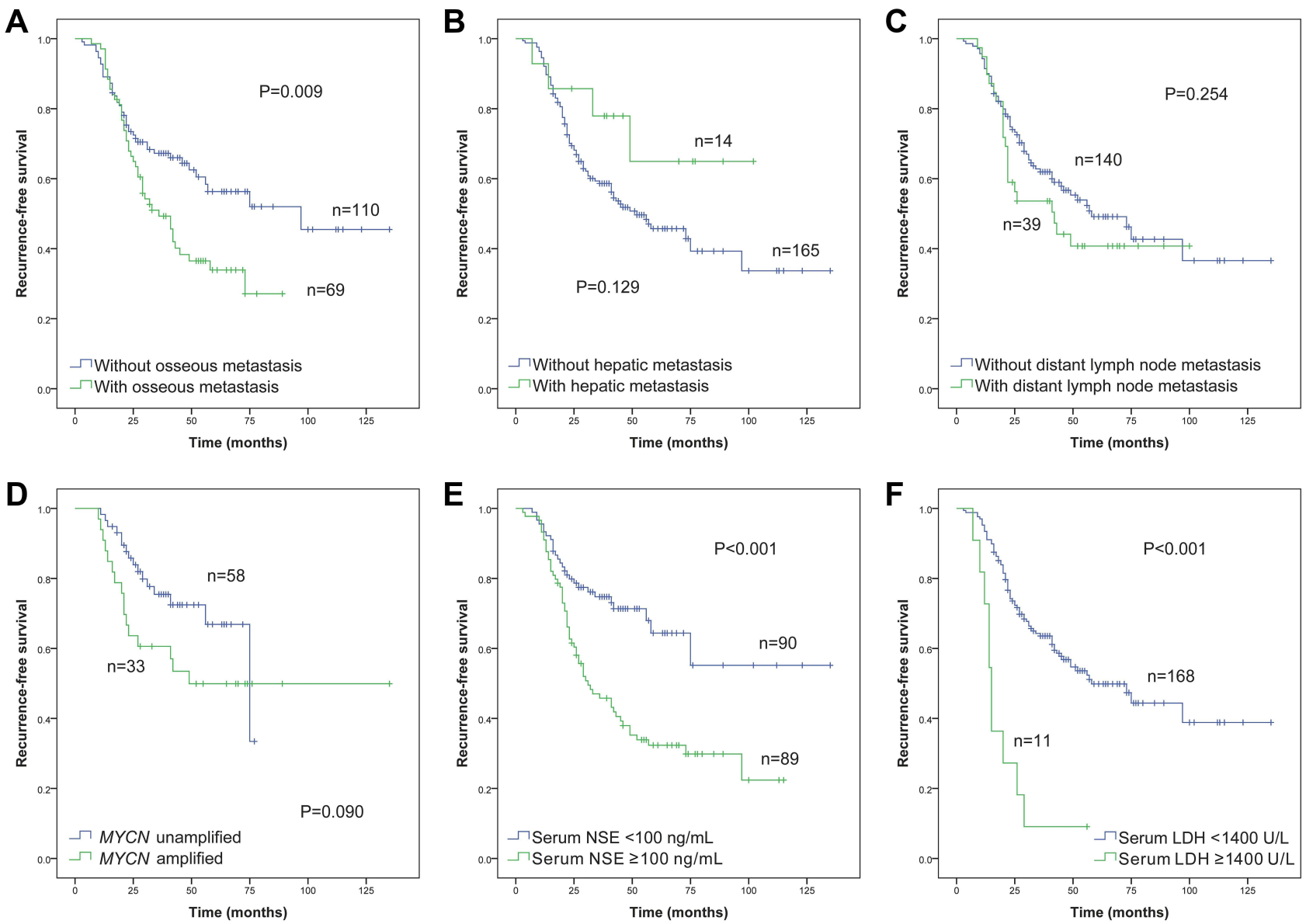

Figure 5 Comparisons of recurrence-free survival by (A) osseous metastasis, (B) hepatic metastasis, (C) distant lymph node metastasis, (D) MYCN status, (E) serum NSE level, and (F) serum LDH level in 179 children with neuroblastoma. (Kaplan-Meier method, $P$ value shown for Log rank test among variables).

The 5-year RFSs were $93.5 \%, 66.4 \%$, and $22.5 \%$ in the lowrisk, intermediate-risk, and high-risk groups, respectively. Comparison of the new recurrence risk stratification with previous stratification systems, including COG risk stratification and INRG classification system, ${ }^{19}$ is shown in Table 7 and Figure 7. The areas under the ROC curve (AUC) of COG risk stratification, INRG classification and the new established recurrence risk stratification were $0.729(95 \%$ CI: $0.654-0.804), 0.700$ (95\% CI: 0.623-0.777), and 0.773 (95\% CI: 0.704-0.842), respectively.

\section{Discussion}

At present, a consensus has been reached to predict clinical prognosis by combining clinical and biological factors. The COG stratified patients into low-, intermediate-, or high-risk categories based upon age, INSS stage, $M Y C N$ status, DNA copy number (ploidy), and histological grading, with each group displaying a risk category that was correlated with clinical events. ${ }^{20}$ The recently proposed INRG classification defined a similar approach with the goal of pretreatment classification. ${ }^{19}$ It is important to note, however, that clinical events in EFS researches include not only disease recurrence but also disease progression, disease death, and accidental death. Therefore, no matter which risk stratification method is used, the risk of tumor recurrence in children with neuroblastoma may not be accurately predicted. In addition, since the mechanism of recurrence after complete response for neuroblastoma remains unclear, and the factors that lead to tumor recurrence may be different from the known adverse prognostic factors, we consider it necessary to investigate the risk factors leading to recurrence independently.

Due to the limitations of the medical technology, there is currently no method of detection of certain biomarkers, such as $M Y C N$ amplification, DNA ploidy, or 11q aberration, in most areas of China, which led to the insufficient feasibility of using COG or INRG stratification to predict the outcomes. Therefore, we aimed to assess the risk of post-remission recurrence by analyzing the features of more readily available clinical data, including age, gender, 
Table 4 Cox Proportional Hazard Model for the Unadjusted and Adjusted Risk Factors of Post-Remission Recurrence in I79 Children with Neuroblastoma

\begin{tabular}{|c|c|c|c|c|c|c|c|}
\hline & \multirow[t]{2}{*}{$\mathbf{n}$} & \multicolumn{3}{|c|}{ Unadjusted } & \multicolumn{3}{|c|}{ Adjusted } \\
\hline & & HR & $95 \% \mathrm{Cl}$ & $P$ value & HR & 95\% Cl & $P$ value \\
\hline \multicolumn{8}{|l|}{ Age (months) } \\
\hline$\geq 18$ & 135 & 4.094 & $1.969-8.51 \mathrm{I}$ & $<0.001$ & 3.017 & $1.411-6.454$ & $0.004^{\mathrm{a}}$ \\
\hline$<18$ & 44 & 1 & & & I & & \\
\hline \multicolumn{8}{|l|}{ INSS stage } \\
\hline $2,3,4 S$ & 81 & 1 & & 0.006 & I & & $0.593^{b}$ \\
\hline 4 & 98 & $\mathrm{I} .897$ & $1.206-2.983$ & & 0.809 & $0.373-1.757$ & \\
\hline \multicolumn{8}{|l|}{ Histological type } \\
\hline Unfavorable histology & 100 & 4.156 & $2.44 \mid-7.077$ & $<0.001$ & 2.813 & $1.58 I-5.006$ & $<0.001^{c}$ \\
\hline Favorable histology & 79 & 1 & & & I & & \\
\hline \multicolumn{8}{|l|}{ Bone marrow metastasis } \\
\hline Yes & 70 & 1.736 & $1.135-2.653$ & 0.011 & 1.025 & $0.566-1.858$ & $0.935^{d}$ \\
\hline No & 109 & 1 & & & 1 & & \\
\hline \multicolumn{8}{|l|}{ Osseous metastasis } \\
\hline Yes & 69 & 1.749 & $1.142-2.679$ & 0.010 & 1.086 & $0.598-1.972$ & $0.788^{\mathrm{e}}$ \\
\hline No & 110 & 1 & & & I & & \\
\hline \multicolumn{8}{|l|}{ MYCN status } \\
\hline Amplified & 33 & 1.809 & $0.900-3.635$ & 0.096 & 1.966 & $0.832-4.646$ & $0.123^{f}$ \\
\hline Not amplified & 58 & I & & & I & & \\
\hline \multicolumn{8}{|l|}{ Serum NSE level $(\mathrm{ng} / \mathrm{mL})$} \\
\hline$\geq 100$ & 89 & 2.468 & $1.564-3.896$ & $<0.001$ & 1.462 & $0.872-2.45$ I & $0.149^{g}$ \\
\hline$<100$ & 90 & 1 & & & I & & \\
\hline \multicolumn{8}{|l|}{ Serum LDH level (U/L) } \\
\hline$\geq 1400$ & 11 & 4.740 & $2.420-9.284$ & $<0.001$ & 3.644 & $1.760-7.547$ & $<0.00 \mathrm{I}^{\mathrm{h}}$ \\
\hline$<1400$ & 168 & I & & & I & & \\
\hline
\end{tabular}

Notes: a Adjusted for INSS stage, histological type, bone marrow metastasis status, osseous metastasis status, serum NSE level, and serum LDH level; ${ }^{\mathrm{b} A d j u s t e d ~ f o r ~ a g e, ~}$ histological type, bone marrow metastasis status, osseous metastasis status, serum NSE level, and serum LDH level; ${ }^{\mathrm{C} A d j u s t e d}$ for age, INSS stage, bone marrow metastasis status, osseous metastasis status, serum NSE level, and serum LDH level; ${ }^{d}$ Adjusted for age, INSS stage, histological type, osseous metastasis status, serum NSE level, and serum LDH level; ${ }^{e}$ Adjusted for age, INSS stage, histological type, bone marrow metastasis status, serum NSE level, and serum LDH level; ${ }^{f}$ Adjusted for age, INSS stage, histological type, bone marrow metastasis status, osseous metastasis status, serum NSE level, and serum LDH level; g Adjusted for age, INSS stage, histological type, bone marrow metastasis status, osseous metastasis status, and serum LDH level; h Adjusted for age, INSS stage, histological type, bone marrow metastasis status, osseous metastasis status, and serum NSE level;

Abbreviations: HR, hazard ratio; Cl, confidence interval; INSS, International Neuroblastoma Staging System; NSE, serum neuron-specific enolase; LDH, serum lactate dehydrogenase.

INSS stage, histological type, primary site, metastasis site, serum NSE level, and serum LDH level. Although some patients lacked $M Y C N$ amplification results in this study, we performed a statistical analysis of the available data. We used tumor recurrence as an endpoint event in the survival analysis, to search for risk factors of postremission recurrence in children with neuroblastoma through a retrospective study.

This study found that children with age $\geq 18$ months, unfavorable histology, and serum LDH level $\geq 1400 \mathrm{U} / \mathrm{L}$ had a significantly higher risk of recurrence than those with age $<18$ months, favorable histology, and serum LDH level $<1400 \mathrm{U} / \mathrm{L}$, respectively.
Although age is a continuous variable, a cutoff point of 12 or 18 months has been customarily used in survival analyses and clinical practice in patients with neuroblastoma. ${ }^{21}$ The traditionally accepted age cutoff of 1 year was based on the observations performed by Breslow in 1971, ie, that age $>1$ year was associated with a worse outcome. ${ }^{22}$ Recent reviews suggest that age of 18 months may be a more clinically relevant predictor of outcome. ${ }^{11,12}$ Combining the results of recent studies and in accordance with the COG and INRG risk stratification, the age threshold in this study was set at 18 months. In this study, children at or older than 18 months had a significantly increased risk of post-remission recurrence. 
Table 5 Comparison of RFSs in 120 Children with High-Risk Neuroblastoma After Initial Complete Response

\begin{tabular}{|c|c|c|c|c|c|}
\hline & n (\%) & I-Year RFS (\%) & 3-Year RFS (\%) & 5-Year RFS (\%) & $P$ value \\
\hline \multicolumn{6}{|l|}{ Age (months) } \\
\hline$\geq 18$ & $107(89.2)$ & 90.7 & 46.1 & 27.3 & 0.095 \\
\hline$<18$ & $13(10.8)$ & 92.3 & 61.5 & 61.5 & \\
\hline \multicolumn{6}{|l|}{ Gender } \\
\hline Male & $68(56.7)$ & 88.2 & 53.3 & 33.2 & 0.519 \\
\hline Female & $52(43.3)$ & 94.2 & 40.9 & 29.1 & \\
\hline \multicolumn{6}{|l|}{ INSS stage } \\
\hline $2,3,4 \mathrm{~S}$ & $29(24.2)$ & 72.4 & 44.6 & 22.6 & 0.188 \\
\hline 4 & $91(75.8)$ & 96.7 & 48.9 & 33.6 & \\
\hline \multicolumn{6}{|l|}{ Histological type } \\
\hline Unfavorable histology & $94(78.3)$ & 89.4 & 45.5 & 24.0 & 0.016 \\
\hline Favorable histology & $26(21.7)$ & 96.2 & 56.3 & 56.3 & \\
\hline \multicolumn{6}{|l|}{ Primary site } \\
\hline Adrenal glands/Retroperitoneum & $99(82.5)$ & 90.9 & 48.3 & 32.8 & 0.396 \\
\hline Others & $21(17.5)$ & 90.5 & 45.9 & 22.9 & \\
\hline \multicolumn{6}{|l|}{ Bone marrow metastasis } \\
\hline Yes & $68(56.7)$ & 95.6 & 48.8 & 34.5 & 0.439 \\
\hline No & $52(43.3)$ & 84.6 & 46.8 & 23.9 & \\
\hline \multicolumn{6}{|l|}{ Osseous metastasis } \\
\hline Yes & $66(55.0)$ & 98.5 & 48.5 & 33.4 & 0.442 \\
\hline No & $54(45.0)$ & 81.5 & 47.4 & 27.9 & \\
\hline \multicolumn{6}{|l|}{ Hepatic metastasis } \\
\hline Yes & $9(7.5)$ & 100.0 & 77.8 & 58.3 & 0.053 \\
\hline No & III (92.5) & 90.1 & 45.4 & 28.9 & \\
\hline \multicolumn{6}{|l|}{ Distant lymph node metastasis } \\
\hline Yes & $37(30.8)$ & 94.6 & 51.1 & 37.5 & 0.608 \\
\hline No & $83(69.2)$ & 89.2 & 46.5 & 28.4 & \\
\hline \multicolumn{6}{|l|}{ MYCN status } \\
\hline Amplified & $28(52.8)$ & 89.3 & 57.1 & 44.0 & 0.757 \\
\hline Not amplified & $25(47.2)$ & 100.0 & 61.7 & 45.0 & \\
\hline \multicolumn{6}{|l|}{ Serum NSE level (ng/mL) } \\
\hline$\geq 100$ & $76(63.3)$ & 92.1 & 42.9 & 27.0 & 0.262 \\
\hline$<100$ & $44(36.7)$ & 88.6 & 56.4 & 38.4 & \\
\hline \multicolumn{6}{|l|}{ Serum LDH level (U/L) } \\
\hline$\geq 1400$ & $9(7.5)$ & 88.9 & II.I & II.I & 0.006 \\
\hline$<1400$ & III (92.5) & 91.0 & 51.0 & 32.9 & \\
\hline \multicolumn{6}{|l|}{ Radiotherapy } \\
\hline Yes & $35(29.2)$ & 91.4 & 37.1 & 25.0 & 0.246 \\
\hline No & $85(70.8)$ & 90.6 & 52.6 & 33.9 & \\
\hline \multicolumn{6}{|l|}{ APBSCT } \\
\hline Yes & $26(21.7)$ & 88.5 & 38.5 & 19.2 & 0.176 \\
\hline No & $94(78.3)$ & 91.5 & 50.8 & 35.7 & \\
\hline
\end{tabular}

Abbreviations: RFS, recurrence-free survival; INSS, International Neuroblastoma Staging System; NSE, serum neuron-specific enolase; LDH, serum lactate dehydrogenase; APBSCT, autologous peripheral blood stem cell transplantation.

Previous studies have shown a poorer EFS in children older than 18 months; however, by independent RFS analysis for age, we found that age is also one of the most important indicators for evaluating risk of recurrence after complete response. With the same INSS stage group, histological type, bone marrow and osseous metastasis status, serum NSE level, and serum LDH level, the risk of post-remission recurrence was 3.017 times higher in children with age $\geq 18$ months than in those with age $<18$ months.

In 1984, Shimada proposed a pathological classification schema that linked the histopathological features of 

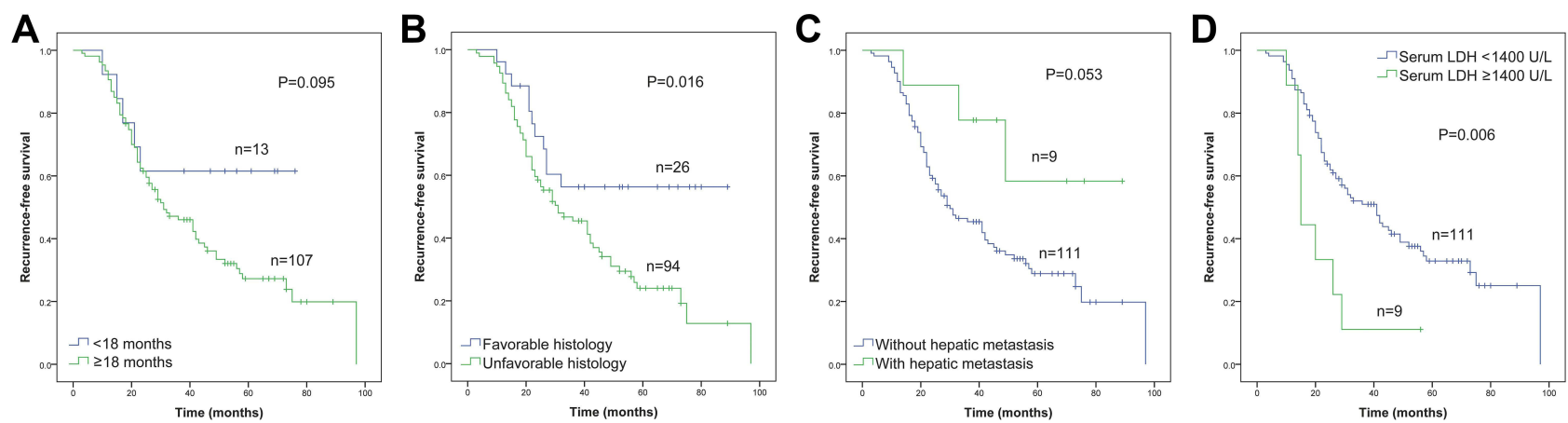

Figure 6 (A) Comparisons of recurrence-free survival by $(\mathbf{A})$ age, $(\mathbf{B})$ histological type, $(\mathbf{C})$ hepatic metastasis, and (D) serum LDH level in I20 children with high-risk neuroblastoma. (Kaplan-Meier method, $P$ value shown for Log rank test among variables).

tumors to clinical behavior, in which tumors are classified based on the age-dependent Schwannian stromal development, neuroblastic differentiation, and the mitosis-karyorrhexis index (MKI). ${ }^{23}$ This classification system has been widely used and has been introduced into the COG and INRG classification systems. In this study, neuroblastoma was divided into groups of favorable and unfavorable histology. After multivariate Cox regression model analysis, unfavorable histology was found to be an independent risk factor for recurrence after complete response. With the same age group, INSS stage group, bone marrow and osseous metastasis status, serum NSE level, and serum LDH level, the risk of recurrence was 2.813 times higher in children with unfavorable histology than in those with favorable histology.
MYC belongs to a family that includes $M Y C L$ and $M Y C N .{ }^{24}$ MYC proteins are part of a network of interacting transcription factors which regulate the expression of multiple genes involved in cell-proliferation, growth, senescence, metabolism, differentiation, and apoptosis. ${ }^{25} \mathrm{MYCN}$ is often overexpressed in tumors of nerve cell origin, including neuroblastoma, retinoblastoma, and medulloblastoma, etc. As one of the earliest genetic markers identified in neuroblastoma, MYCN amplification is often associated with poor prognosis. ${ }^{24,26}$ Our study showed that there was no significant difference in RFSs between patients with and without MYCN amplification, and MYCN amplification was not an independent risk factor for post-remission recurrence in children with neuroblastoma after multivariate analysis. We found that $M Y C N$ amplification did not appear to be

Table 6 Cox Proportional Hazard Model for the Unadjusted and Adjusted Risk Factors of Post-Remission Recurrence in I20 Children with High-Risk Neuroblastoma

\begin{tabular}{|c|c|c|c|c|c|c|c|}
\hline & \multirow[t]{2}{*}{$\mathbf{n}$} & \multicolumn{3}{|c|}{ Unadjusted } & \multicolumn{3}{|c|}{ Adjusted } \\
\hline & & HR & $95 \% \mathrm{Cl}$ & $P$ value & HR & $95 \% \mathrm{Cl}$ & $P$ value \\
\hline \multicolumn{8}{|l|}{ Age (months) } \\
\hline$\geq 18$ & & 2.115 & $0.853-5.243$ & 0.106 & 1.887 & $0.7 \mid 4-4.988$ & $0.200^{\mathrm{a}}$ \\
\hline$<18$ & & I & & & 1 & & \\
\hline \multicolumn{8}{|l|}{ Histological type } \\
\hline Unfavorable histology & & 2.148 & I.I30-4.082 & 0.020 & 1.863 & $0.964-3.600$ & $0.064^{b}$ \\
\hline Favorable histology & & I & & & 1 & & \\
\hline \multicolumn{8}{|l|}{ Hepatic metastasis } \\
\hline Yes & & I & & 0.068 & I & & $0.114^{c}$ \\
\hline No & & 2.939 & $0.924-9.350$ & & 2.563 & $0.797-8.235$ & \\
\hline \multicolumn{8}{|l|}{ Serum LDH level (U/L) } \\
\hline$\geq 1400$ & & 2.671 & $1.273-5.605$ & 0.009 & 2.803 & $1.280-6.140$ & $0.010^{d}$ \\
\hline$<1400$ & & I & & & I & & \\
\hline
\end{tabular}

Notes: ${ }^{a}$ Adjusted for histological type, hepatic metastasis status, and serum LDH level; ${ }^{\mathrm{b}}$ Adjusted for age, hepatic metastasis status, and serum LDH level; ${ }^{\mathrm{c} A d j u s t e d ~ f o r ~ a g e, ~}$

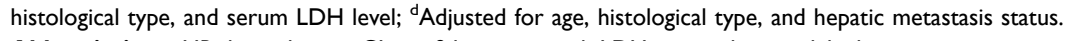

Abbreviations: $\mathrm{HR}$, hazard ratio; $\mathrm{Cl}$, confidence interval; $\mathrm{LDH}$, serum lactate dehydrogenase. 
Table 7 The New Recurrence Risk Stratification System and Previous Risk Classification Systems in Predicting Post-Remission Recurrence in Children with Neuroblastoma

\begin{tabular}{|c|c|c|c|c|}
\hline & n (\%) & 5-Year RFS (\%) & $P$ value & AUC $(95 \% \mathrm{CI})$ \\
\hline \multicolumn{5}{|c|}{ COG risk stratification } \\
\hline Low risk & $10(5.6)$ & 88.9 & 0.705 (low vs intermediate) & $0.729(0.654$ \\
\hline Intermediate risk & $49(27.4)$ & 85.1 & & $-0.804)$ \\
\hline High risk & $120(67.0)$ & 31.2 & $<0.05$ (others) & \\
\hline \multicolumn{5}{|c|}{ INRG risk classification } \\
\hline Very low risk & $31(17.3)$ & 86.2 & $0.57 \mathrm{I}$ (very low vs low) & $0.700(0.623$ \\
\hline Low risk & $13(7.3)$ & 83.9 & 0.056 (low vs intermediate) & $-0.777)$ \\
\hline Intermediate risk & $37(20.7)$ & 42.3 & 0.376 (intermediate vs high) & \\
\hline High risk & $98(54.7)$ & 33.6 & $<0.01$ (others) & \\
\hline \multicolumn{5}{|c|}{ New recurrence risk stratification } \\
\hline Low risk & $32(17.9)$ & 93.5 & $<0.01$ & $0.773(0.704$ \\
\hline Intermediate risk & $55(30.7)$ & 66.4 & & $-0.842)$ \\
\hline High risk & $92(51.4)$ & 22.5 & & \\
\hline
\end{tabular}

Abbreviations: RFS, recurrence-free survival; AUC: area under the ROC curve; COG, Children's Oncology Group; INRG, International Neuroblastoma Risk Group.

associated with post-remission recurrence in children with neuroblastoma; however, further conclusions need to be drawn from large, multicenter studies.

Specific laboratory biomarkers may also play an important role in the study of survival prognosis. NSE, VMA, and HVA are commonly used biomarkers for evaluating the prognosis of neuroblastoma, among which NSE is the most studied biomarker. Previous studies suggested that serum NSE levels $\geq 100 \mathrm{ng} / \mathrm{mL}$ were associated with a poor outcome. ${ }^{13,14}$ Although a few recent studies have explored the application of serum NSE level in predicting the recurrence or progression of neuroblastoma, ${ }^{27}$ the relationship between serum NSE level and recurrence remains unclear. In our study, although children with serum NSE level $\geq 100 \mathrm{ng} / \mathrm{mL}$ had significantly higher recurrence rates than those with serum NSE level $<100 \mathrm{ng} / \mathrm{mL}$, serum NSE level at initial diagnosis was not an independent risk factor for post-remission recurrence in neuroblastoma. It is known that the sensitivity and specificity of NSE in the diagnosis of neuroblastoma are limited, ${ }^{15}$ and that the monitoring of tumor biomarkers alone cannot reliably predict survival outcomes, including recurrence; however, this parameter could still be useful for the clinical prediction of outcome in children with neuroblastoma if a true relationship between serum NSE and recurrence is proven.

As a marker of tissue injury and disease, serum LDH has been considered to be closely related to the prognosis of solid tumors in recent years. ${ }^{28-30}$ A recent study from INRG have shown that serum LDH are strongly prognostic in children with neuroblastoma. ${ }^{16}$ The determination of serum LDH has the advantages of convenience, rapidness, reliability and economy. Thus, in low- and middle-income countries or regions where genetic and chromosomal tests are not available, serum LDH may be an important biomarker for the preliminary assessment of prognosis in children with neuroblastoma. Based on the analysis of
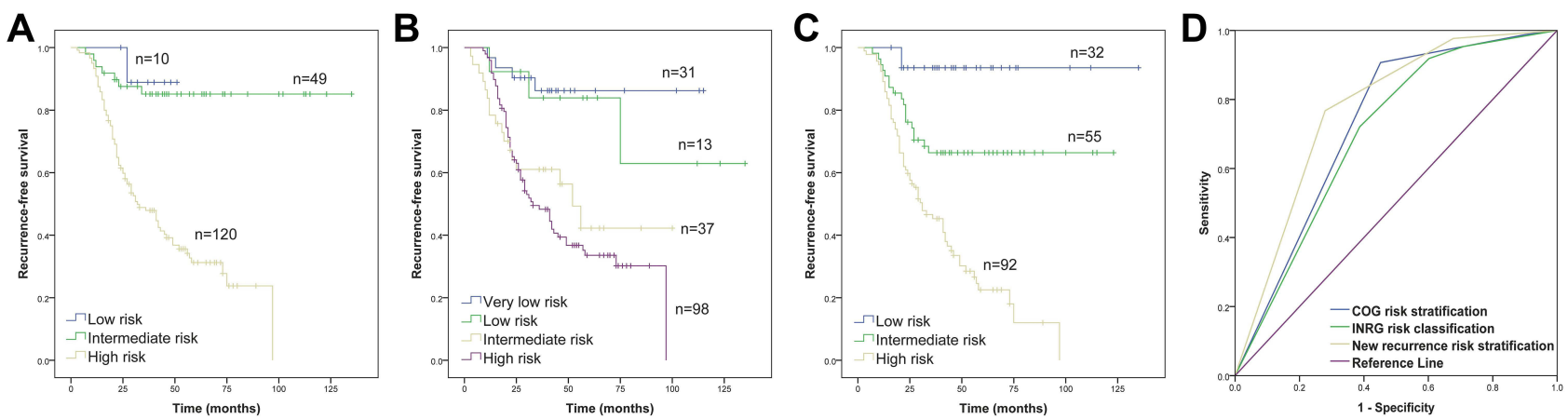

Figure 7 Recurrence-free survival of 179 children with neuroblastoma based on (A) COG risk stratification, (B) INRG classification system, and (C) the new recurrence risk stratification; (D) Comparison of ROC curves among the three stratification systems. 
serum LDH before treatment, this study found that the incidence of post-remission recurrence was significantly increased in children with serum LDH $\geq 1400 \mathrm{U} / \mathrm{L}$; meanwhile, serum LDH is an independent risk factor for postremission recurrence in children with neuroblastoma. With the same age group, INSS stage group, histological type, bone marrow and osseous metastasis status, and serum NSE level, the risk of recurrence was 3.644 times higher in children with $\mathrm{LDH} \geq 1400 \mathrm{U} / \mathrm{L}$ than in those with $\mathrm{LDH}$ $<1400 \mathrm{U} / \mathrm{L}$. For the children with high-risk neuroblastoma, serum $\mathrm{LDH} \geq 1400 \mathrm{U} / \mathrm{L}$ was the only independent risk factor for recurrence. With the same age group, histological type, and hepatic metastasis status, the risk of recurrence was 2.803 times higher in children with $\mathrm{LDH} \geq 1400$ $\mathrm{U} / \mathrm{L}$ than in those with $\mathrm{LDH}<1400 \mathrm{U} / \mathrm{L}$.

Some of our expected independent risk factors for recurrence, such as INSS stage, bone marrow metastasis, osseous metastasis, hepatic metastasis, etc., did not achieve the results we expected, ie, had no significant effect on recurrence. In the assessment of risk factors, we did not simply divide the tumor into groups with and without metastatic disease, because we considered that there was a special $4 \mathrm{~S}$ or MS stage and that hepatic metastasis might be a protective factor for recurrence; however, regardless of the location of the metastatic lesions, there was no significant effect on post-remission recurrence. Although INSS stage and metastases were known as important prognostic factors, ${ }^{31,32}$ they had no significant impact on tumor recurrence once a patient achieves complete response.

Different from the low- and intermediate-risk children, children in the high-risk group received radiotherapy and APBSCT as part of their treatment regimen; moreover, the recurrence rate of the high-risk group was much higher than that of the low- and intermediate-risk group, so we analyzed them separately. In the high-risk group, serum $\mathrm{LDH} \geq 1400 \mathrm{U} / \mathrm{L}$ was the only independent risk factor for recurrence. At the same time, it was found that APBSCT and radiotherapy did not reduce the post-remission recurrence rate in high-risk children. Currently, the use of myeloablative chemotherapy with stem-cell transplantation (SCT) for neuroblastoma has always been controversial, which may improve the outcome while increasing the risk of treatment-associated death for high-risk neuroblastoma. ${ }^{33}$ Although several studies have shown an improved EFS using SCT, outcomes still remain poor. ${ }^{34-37}$ In this study, APBSCT was performed in the high-risk children after initial complete response, and the recurrence rate was not significantly reduced compared with that in the non-APBSCT high-risk children. Based on the above results, we believe that if a definitive conclusion is drawn that, APBSCT cannot reduce the recurrence rate in high-risk children, it should be carefully selected for the treatment of high-risk neuroblastoma after initial complete response.

After analyzing the risk factors for recurrence, we established a new post-remission recurrence risk stratification system for children with neuroblastoma based on three independent risk factors: age $\geq 18$ months, unfavorable histology, and LDH $\geq 1400 \mathrm{U} / \mathrm{L}$. As was shown in the results, children in the low-risk and the intermediate-risk group did not show a significant different RFS in the COG risk stratification system. For INRG classification system, there were no significant differences in RFS among all adjacent risk groups. Children in the newly established stratification system showed significant differences in RFS among the low-, intermediate-, and high-risk groups. By comparing the AUC of the three risk stratification systems, the newly established recurrence risk stratification system has diagnostic advantages in predicting postremission recurrence in children with neuroblastoma. Meanwhile, due to the fact that it does not need to carry out gene and chromosome testing, the new stratification system has the advantages of economy, simplicity, rapidness and efficiency, especially suitable for low- and middle-income countries or regions.

Children with neuroblastoma in complete response have a significantly higher risk of recurrence than those with other malignant solid tumors. Recurrence of the tumor implies an increase in mortality and a huge waste of clinical and financial resources. Post-remission recurrence of neuroblastoma not only represents a large financial burden to patients but also places a heavy psychological pressure on clinicians. Once patients are at high risk for recurrence, initial and post-remission treatment strategies should be adjusted to prevent tumor recurrence. With this study, we aimed to draw attention to independent researches on the risk of post-remission recurrence in children with neuroblastoma, rather than just assess the factors that affect EFS or OS. Although age, histological type, and serum LDH level played an important role in the post-remission recurrence of neuroblastoma in our study, additional research is needed to reach a definitive conclusion, which may have a positive impact on the long-term survival of children with neuroblastoma after complete response. 


\section{Conclusion}

Age $\geq 18$ months, unfavorable histology, and serum LDH level $\geq 1400 \mathrm{U} / \mathrm{L}$ are independent risk factors for postremission recurrence in children with neuroblastoma. A newly established recurrence risk stratification has diagnostic advantages in predicting recurrence in children with neuroblastoma after complete response, which is especially suitable for low- and middle-income countries or regions.

\section{Acknowledgments}

The authors sincerely thank Qun Wang, Weishan Ren, TingTing Liu, Yanan Gao, Tao Han and Liping Chen for their constructive suggestions and technical support on this study. This research received no external funding.

\section{Disclosure}

The authors report no conflicts of interest in this work.

\section{References}

1. Park JR, Eggert A, Caron H. Neuroblastoma: biology, prognosis, and treatment. Hematol Oncol Clin North Am. 2010;24(1):65-86. doi:10.1016/j.hoc.2009.11.011

2. Gutierrez JC, Fischer AC, Sola JE, Perez EA, Koniaris LG. Markedly improving survival of neuroblastoma: a 30-year analysis of 1646 patients. Pediatr Surg Int. 2007;23(7):637-646. doi:10.1007/ s00383-007-1933-7

3. Maris JM. Recent advances in neuroblastoma. $N$ Engl $J$ Med. 2010;362:2202-2211. doi:10.1056/NEJMra0804577

4. Basta NO, Halliday GC, Makin G, et al. Factors associated with recurrence and survival length following relapse in patients with neuroblastoma. Br J Cancer. 2016;115(9):1048-1057. doi:10.1038/ bjc. 2016.302

5. Dübbers M, Simon T, Berthold F, et al. Retrospective analysis of relapsed abdominal high-risk neuroblastoma. $J$ Pediatr Surg. 2018;53:558-566. doi:10.1016/j.jpedsurg.2017.09.002

6. London WB, Castel V, Monclair T, et al. Clinical and biologic features predictive of survival after relapse of neuroblastoma: a report from the International Neuroblastoma Risk Group project. $J$ Clin Oncol. 2011;29(24):3286-3292. doi:10.1200/JCO.2010.3 4.3392

7. Murphy JM, Lim II, Farber BA, et al. Salvage rates after progression of high-risk neuroblastoma with a soft tissue mass. J Pediatr Surg. 2016;51(2):285-288. doi:10.1016/j.jpedsurg.2015.10.075

8. Zhu J, Wang J, Zhen ZJ, et al. Brain metastasis in children with stage 4 neuroblastoma after multidisciplinary treatment. Chin J Cancer. 2015;34:531-537. doi:10.1186/s40880-015-0038-2

9. Brodeur GM, Pritchard J, Berthold F, et al. Revisions of the international criteria for neuroblastoma diagnosis, staging, and response to treatment. $J$ Clin Oncol. 1993;11:1466-1477. doi:10.1200/ JCO.1993.11.8.1466

10. Shimada H, Ambros IM, Dehner LP, et al. The International Neuroblastoma Pathology Classification (the Shimada system). Cancer. 1999;86:364-372. doi:10.1002/(SICI)1097-0142(19990715) $86: 2<364:: A I D-C N C R 21>3.0 . C O ; 2-7$
11. George RE, London WB, Cohn SL, et al. Hyperdiploidy plus NonamplifiedMYCN confers a favorable prognosis in children 12 to 18 months old with disseminated neuroblastoma: a pediatric oncology group study. J Clin Oncol. 2005;23(27):6466-6473. doi:10.1200/ JCO.2005.05.582

12. Schmidt ML, Lal A, Seeger RC, et al. Favorable prognosis for patients 12 to 18 Months of age with stage 4 nonamplified MYCN neuroblastoma: a children's cancer group study. J Clin Oncol. 2005;23(27):6474-6480. doi:10.1200/JCO.2005.05.183

13. Ishiguro $Y$, Kato K, Ito T, Nagaya M, Yamada N, Sugito T. Nervous system-specific enolase in serum as a marker for neuroblastoma. Pediatrics. 1983;72(5):696-700. doi:10.1542/peds.72.5.696

14. Zeltzer PM, Marangos PJ, Parma AM, et al. Raised neuron-specific enolase in serum of children with metastatic neuroblastoma. A report from the Children's Cancer Study Group. Lancet. 1983;2 (8346):361-363. doi:10.1016/S0140-6736(83)90342-2

15. Ferraro S, Braga F, Luksch R, Terenziani M, Caruso S, Panteghini M. Measurement of serum neuron-specific enolase in neuroblastoma: is there a clinical role? Clin Chem. 2020;66(5):667-675. doi:10.1093/ clinchem/hvaa073

16. Moroz V, Machin D, Hero B, et al. The prognostic strength of serum LDH and serum ferritin in children with neuroblastoma: a report from the International Neuroblastoma Risk Group (INRG) project. Pediatr Blood Cancer. 2020;67(8):e28359. doi:10.1002/pbc.28359

17. Maris JM, Hogarty MD, Bagatell R, Cohn SL. Neuroblastoma. Lancet. 2007;369(9579):2106-2120. doi:10.1016/S0140-6736(07) 60983-0

18. Miller AB, Hoogstraten B, Staquet M, Winkler A. Reporting results of cancer treatment. Cancer. 1981;47(1):207-214. doi:10.1002/10970142(19810101)47:1<207::AID-CNCR2820470134>3.0.CO;2-6

19. Cohn SL, Pearson AD; INRG Task Force, et al. The International Neuroblastoma Risk Group (INRG) classification system: an INRG Task Force report. J Clin Oncol. 2009;27(2):289-297. doi:10.1200/ JCO.2008.16.6785.

20. Park JR, Bagatell R; COG Neuroblastoma Committee, et al. Children's Oncology Group's 2013 blueprint for research: neuroblastoma. Pediatr Blood Cancer. 2013;60:985-993. doi:10.1002/ pbc. 24433

21. London WB, Castleberry RP, Matthay KK, et al. Evidence for an age cutoff greater than 365 days for neuroblastoma risk group stratification in the Children's Oncology Group. J Clin Oncol. 2005;23 (27):6459-6465. doi:10.1200/JCO.2005.05.571

22. Breslow N, McCann B. Statistical estimation of prognosis for children with neuroblastoma. Cancer Res. 1971;31(12):2098-2103.

23. Shimada H, Chatten J, Newton WA Jr, et al. Histopathologic prognostic factors in neuroblastic tumors: definition of subtypes of ganglioneuroblastoma and an age-linked classification of neuroblastomas. J Natl Cancer Inst. 1984;73(2):405-416. doi:10.1093/jnci/73.2.405

24. Brodeur GM, Seeger RC, Schwab M, Varmus HE, Bishop JM. Amplification of N-myc in untreated human neuroblastomas correlates with advanced disease stage. Science. 1984;224 (4653):1121-1124. doi:10.1126/science.6719137

25. Otte J, Dyberg C, Pepich A, Johnsen JI. MYCN function in neuroblastoma development. Front Oncol. 2021;10:624079. doi:10.3389/ fonc.2020.624079

26. Schwab M, Ellison J, Busch M, Rosenau W, Varmus HE, Bishop JM. Enhanced expression of the human gene N-myc consequent to amplification of DNA may contribute to malignant progression of neuroblastoma. Proc Natl Acad Sci U S A. 1984;81:4940-4944. doi:10.1073/pnas.81.15.4940

27. Simon T, Hero B, Hunneman DH, Berthold F. Tumour markers are poor predictors for relapse or progression in neuroblastoma. Eur $J$ Cancer. 2003;39(13):1899-1903. doi:10.1016/S0959-8049(03) 00376-9 
28. Petrelli F, Cabiddu M, Coinu A, et al. Prognostic role of lactate dehydrogenase in solid tumors: a systematic review and meta-analysis of 76 studies. Acta Oncol. 2015;54(7):961-970. doi:10.3109/0284186X.2015.1043026

29. Zhang J, Yao YH, Li BG, Yang Q, Zhang PY, Wang HT. Prognostic value of pretreatment serum lactate dehydrogenase level in patients with solid tumors: a systematic review and meta-analysis. Sci Rep. 2015;5:9800. doi:10.1038/srep09800

30. Konjević G, Jurisić V, Jakovljević B, Spuzić I. Lactate dehydrogenase (LDH) in peripheral blood lymphocytes (PBL) of patients with solid tumors. Glas Srp Akad Nauka Med. 2002;47:137-147.

31. Mossé YP, Deyell RJ, Berthold F, et al. Neuroblastoma in older children, adolescents and young adults: a report from the International Neuroblastoma Risk Group project. Pediatr Blood Cancer. 2014;61:627-635. doi:10.1002/pbc.24777

32. DuBois SG, Kalika Y, Lukens JN, et al. Metastatic sites in stage IV and IVS neuroblastoma correlate with age, tumor biology, and survival. J Pediatr Hematol Oncol. 1999;21:181-189. doi:10.1097/ 00043426-199905000-00005

33. Berthold F, Boos J, Burdach S, Hero B. Myeloablative megatherapy with autologous stem-cell rescue versus oral maintenance chemotherapy as consolidation treatment in patients with high-risk neuroblastoma: a randomised controlled trial. Lancet Oncol. 2005;6:649-658. doi:10.1016/S1470-2045(05)70291-6
34. Ladenstein R, Philip T, Lasset C, et al. Multivariate analysis of risk factors in stage 4 neuroblastoma patients over the age of one year treated with megatherapy and stem-cell transplantation: a report from the European Bone Marrow Transplantation Solid Tumor Registry. J Clin Oncol. 1998;16(3):953-965. doi:10.1200/JCO.1998.16.3.953

35. Saarinen-Pihkala UM, Hovi L, Koivusalo A, et al. Thiotepa and melphalan based single, tandem, and triple high dose therapy and autologous stem cell transplantation for high risk neuroblastoma. Pediatr Blood Cancer. 2012;59:1190-1197. doi:10.1002/ pbc. 24173

36. Okamoto Y, Kodama Y, Nishikawa T, Kawano Y. Persistent positive metaiodobenzylguanidine scans after autologous peripheral blood stem cell transplantation may indicate maturation of stage 4 neuroblastoma. Pediatr Hematol Oncol. 2017;34:157-164. doi:10.1080/08880018.2017.1348414

37. Kushner BH, Ostrovnaya I, Cheung IY, Cheung NK. Lack of survival advantage with autologous stem-cell transplantation in high-risk neuroblastoma consolidated by anti-GD2 immunotherapy and isotretinoin. Oncotarget. 2016;7:4155-4166. doi:10.18632/ oncotarget. 6393

\section{Publish your work in this journal}

Cancer Management and Research is an international, peer-reviewed open access journal focusing on cancer research and the optimal use of preventative and integrated treatment interventions to achieve improved outcomes, enhanced survival and quality of life for the cancer patient.
The manuscript management system is completely online and includes a very quick and fair peer-review system, which is all easy to use. Visit http://www.dovepress.com/testimonials.php to read real quotes from published authors. 